\title{
Determinantes do Desmatamento nos Municípios do Arco Verde - Amazônia Legal: uma abordagem econométrica
}

\author{
Linda Mendes Delazeri*
}

\begin{abstract}
Resumo: A Amazônia Legal é, historicamente, um território marcado por questões ambientais resultado da exploração intensa de seus recursos naturais. Dentre os municípios que compõem essa região, 49 se destacam por apresentar altos índices de desmatamento. Dada a importância da Amazônia para a manutenção dos serviços ecológicos, o objetivo deste artigo é determinar as principais causas do desmatamento nestes municípios entre 2008 e 2012 utilizando a modelagem de Efeitos Fixos. Os resultados indicam que a pecuária é o principal determinante no incremento do desmatamento nos municípios analisados e a expansão da lavoura de soja não é significativa para explicar o desmatamento.
\end{abstract}

Palavras - chave: Desmatamento, Amazônia, Econometria.

Classificação JEL: C01, Q,20, Q23.

Determinants of Deforestation in the Municipalities of the Arcoverde - Legal Amazon: an econometric approach

\begin{abstract}
The Legal Amazon is historically a territory marked by environmental concerns about the intense exploitation of its natural resources. Among the municipalities that compose this region, 49 are highlighted for having high rates of deforestation. Given the importance of the Amazon in supplying ecological services, the objective of this paper is to determine the main causes of deforestation in these municipalities between 2008 and 2012 using the modeling of Fixed Effects. The results indicate that livestock is the main factor in the increase of deforestation and the expansion of the soybean crop is not significant in explaining deforestation in the cities analyzed.
\end{abstract}

Keywords: Deforestation, Amazon, Econometrics.

JEL Classification: C01, Q,20, Q23.

Mestranda em Economia Aplicada, Departamento de Economia Rural, Universidade Federal de Viçosa. E-mail: lindelazeri@yahoo.com.br 


\section{Introdução}

A floresta Amazônica representa cerca de um terço das florestas tropicais do mundo, contém mais da metade da biodiversidade mundial e ajuda a manter o equilíbrio climático com o processo de evaporação e transpiração das árvores. Desempenha ainda um papel imprescindível na manutenção de serviços ecológicos e funciona como um armazém de carbono (IPAM, 2014). Dados todos os benefícios da floresta Amazônica, uma das principais questões que preocupam os ambientalistas e os especialistas em mudanças climáticas são os efeitos do desflorestamento na perda da biodiversidade e na intensificação do efeito estufa.

A crescente produção de carne, grãos, madeira e outros produtos florestais para atender as demandas interna e externa tem contribuído para mudanças sociais e econômicas significativas na região amazônica. Como resultado dessa produção crescente, as áreas de floresta nativa estão cedendo lugar para as áreas de pastagens e áreas agrícolas.

Diversos trabalhos buscaram explicar as causas do desmatamento na Amazônia e apresentaram um forte consenso em relação às principais forças determinantes no desmatamento nas décadas de 1960 a 1980. Destacaram-se as políticas públicas, em especial os incentivos fiscais e empreendimentos privados na Amazônia, os créditos rurais subsidiados, os programas de colonização agrícola e os investimentos em infraestrutura, os quais atraíram empreendedores e milhares de migrantes em busca de terras para a região. Ao longo da década de 1990, entretanto, o poder explicativo da maioria dessas variáveis para com o desmatamento na região foi reduzido ou mesmo eliminado. Não obstante, as taxas de desflorestamento permaneceram altas, o que poderia indicar a presença de outras forças subjacentes determinando o desflorestamento (RODRIGUES, 2004).

A hiperinflação no início da década de 1990 resultou em uma supervalorização da terra, com consequente aumento dos preços, que atingiram os valores mais altos em 1995 e tornou a especulação de terras um negócio atrativo. Os preços em alta garantiram à terra o papel de proteção contra a inflação, o que resultou no desmatamento de novas áreas para a formação de pastagens. Além disso, a implantação do Plano Real, em 1994, possibilitou o aumento do consumo de alimentos, incluindo a carne bovina, devido à estabilização econômica resultante da queda da inflação; e a liberalização econômica na década de 1990 fez com que a cadeia agroindustrial de carne bovina ganhasse espaço no cenário mundial (FEARNSIDE, 2002; FEARNSIDE, 2005; RODRIGUES, 2004; MELZ et al., 2014).

Muitos estudos que abordaram a temática do desmatamento da Amazônia desenvolvidos até a década de 1990 determinaram suas principais causas desde que o processo de ocupação intensa da região teve início. Conforme será discutido adiante, os trabalhos concluíram que a expansão da soja e da pecuária, silvicultura e obras de infraestrutura foram as principais causas do desmatamento na região amazônica.

Dentro da Amazônia Legal, a região do Arco Verde ou região dos municípios prioritários se destaca por concentrar os municípios com os maiores índices 
de desflorestamento. Entretanto, poucos estudos se preocuparam em determinar e quantificar as causas do desflorestamento nesta região. Dados apontam que de 2005 até os dias atuais, o desmatamento na Amazônia reduziu cerca de 79\% devido principalmente à políticas como o Plano de Ação para a Prevenção e Controle do Desmatamento na Amazônia Legal (PPCDAm), o que indica que a configuração do desmatamento, bem como os seus determinantes, podem não ser os mesmos ou não ter a mesma intensidade daqueles mostrados pela literatura.

Sendo assim, o presente artigo tem como objetivo principal determinar as causas do desmatamento no Arco Verde. Além das variáveis já tradicionalmente utilizadas para explicar o desmatamento na Amazônia, este artigo irá incluir outras variáveis subjacentes, tais como a presença de instituições reguladores no âmbito municipal e o total de matrículas efetuadas na educação de jovens e adultos, a fim de compreender mais profundamente os determinantes do desmatamento na Amazônia entre os anos 2008 e 2012. A hipótese levantada neste estudo é que a pecuária e a soja continuam sendo as principais causas do desmatamento nos municípios do Arco Verde.

\subsection{Histórico da ocupação territorial na Amazônia Legal}

A Amazônia é, historicamente, um território constituído basicamente por disputas pela exploração de recursos naturais. Essa característica remonta ao período colonial, quando Portugal e Espanha iniciaram expedições a fim de explorar as riquezas naturais da região.

Ao longo dos séculos, a região passou por ciclos de crescimento intenso, especialmente durante o ciclo da borracha entre meados do século XIX e início do século XX. Foi, porém, entre aos anos 1960 e 1970, durante o Regime Militar, que a modernização econômica colocou a região amazônica no centro do debate nacional sobre ocupação territorial e exploração de riquezas. Sob o slogan "Integrar para não entregar", os governos militares fizeram projetos de infraestrutura e programas para ocupar e controlar a região, como políticas de incentivos fiscais e crédito rural. Nesse período houve grande estímulo à migração, principalmente dos nordestinos, para que a necessidade de mão-de-obra em projetos mineradores, agropecuários $\mathrm{e}$ madeireiros que se instalavam na Amazônia fosse atendida. A Marcha para o Oeste viabilizou a implantação de projetos agropecuários, de colonização e expansão do agronegócio em regiões de fronteira, o que fez com que empresas de grande porte predominassem de modo ostensivo a política de terras executada pelo governo federal (MACHADO, 2009).

De acordo com Oliveira (2005), os incentivos fiscais são considerados os principais responsáveis pelo desmatamento inicial na região amazônica. Durante o período de ocupação intensa, mais de 580 projetos agropecuários foram incentivados pela Superintendência de Desenvolvimento da Amazônia (SUDAM), sendo que Pará e Mato Grosso foram os estados que receberam a maior parte destes projetos. 
Tabela 1: Projetos financiados pela SUDAM por Estado.

\begin{tabular}{c|c|c}
\hline Estado & Número & Percentual \\
\hline Pará & 212 & 36,5 \\
\hline Mato Grosso & 207 & 35,6 \\
\hline Goiás $^{1}$ & 52 & 9,0 \\
\hline Amapá & 29 & 5,0 \\
\hline Maranhão & 24 & 4,1 \\
\hline Amazonas & 22 & 3,8 \\
\hline Acre & 18 & 3,1 \\
\hline Rondônia & 11 & 1,9 \\
\hline Roraima & 6 & 1,0 \\
\hline Total & 581 & 100
\end{tabular}

Na década de 1980 a recessão econômica impossibilitou que os recursos públicos e privados mantivessem os programas de desenvolvimento amazônico, contribuindo para a queda da taxa de desmatamento nos anos de 1990 e 1991. Porém, com a recuperação econômica após a implantação do Plano Real, em 1994 o desmatamento voltou a crescer (MARTINS et al., 2010). O aumento da renda real dos brasileiros, propiciada pela estabilidade de preços após a implantação do Plano Real, possibilitou o aumento do consumo de alimentos, inclusive o de carne bovina. A especulação de terras na primeira metade da década de 1990, que funcionou como hedge inflacionário, fez com que o preço da terra atingisse valores exorbitantes, resultando na expansão do desmatamento para novas áreas. Além disso, a abertura comercial com consequente inserção do agronegócio brasileiro no cenário mundial, bem como a criação dos mercados comuns, como MERCOSUL, ALCA e União Europeia, deram novo delineamento à produção de carne bovina e, como consequência, ao desmatamento no Amazônia.

A Figura 1 exibe a evolução do desmatamento na Amazônia Legal desde o início da sua medição, em 1988, até o ano 2000.

1 O território do estado de Goiás compreende também o território do atual estado de Tocantins. A separação dos estados de Goiás e de Tocantins foi feita apenas em 1988, período posterior ao considerado na Tabela 1. 
Figura 1: Evolução do desmatamento $\left(\mathrm{em} \mathrm{km}^{2}\right)$ na Amazônia Legal entre 1988 e 2000.

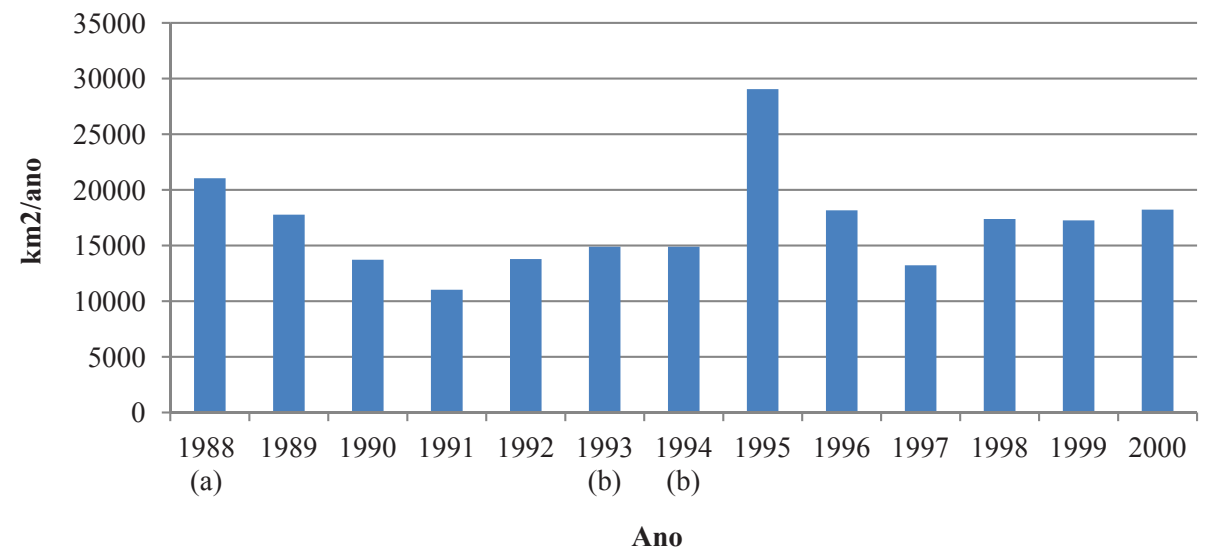

(a) Média entre 1977 e 1988, (b) 3 Média entre 1993 e 1994.

Fonte: PRODES, 2014.

A intensa exploração da região surtiu alguns efeitos indesejáveis ao crescimento econômico, como desmatamento, grilagem de terras e intensificação de conflitos socioambientais com os habitantes tradicionais do território. A partir da década de 1980, a violência no meio rural resultante do sistema fundiário e os alarmantes índices de desmatamento provocaram forte mobilização mundial em defesa da floresta amazônica e dos meios de vida sustentáveis.

Nas décadas mais recentes surgiram movimentos dos setores afetados pelo crescimento não sustentável que impulsionaram a criação de políticas regulatórias voltadas especificamente para a região, como a demarcação de terras indígenas, a criação de áreas protegidas, combate e controle do desmatamento e regularização fundiária.

\subsection{Amazônia Legal e Arco Verde}

O conceito de Amazônia Legal foi instituído em 1953 com o intuito de melhor planejar o desenvolvimento social e econômico da região amazônica. A Amazônia Legal é uma área que corresponde a 59\% do território brasileiro e engloba a totalidade de oito estados (Acre, Amapá, Amazonas, Mato Grosso, Pará, Rondônia, Roraima e Tocantins) e parte do Estado do Maranhão (a oeste do meridiano de $44^{\circ}$ ), com área total de $5.217 .423 \mathrm{~km}^{2}$. Segundo o Censo 2010, nesta área viviam cerca de 24 milhões de pessoas distribuídas em 775 municípios, correspondendo a aproximadamente 12,3\% do total de habitantes do Brasil (SUDAM, 2014).

\footnotetext{
A média do período entre 1977 e 1988 é utilizada, pois não havia medição anual do antes de 1989.

3 Utiliza-se a média do desmatamento para os anos de 1993 e 1994 devido à ausência da estimativa para o ano de 1993.
} 
A região do Arco Verde é composta por 49 municípios da Amazônia Legal que, de acordo com o Programa de Cálculo do Desflorestamento da Amazônia (PRODES), apresentam as maiores taxas de desflorestamento da região. O Ministério do Meio Ambiente publica anualmente uma lista de municípios a serem atendidos, identificados com base nos índices de desmatamento apresentados no período e são considerados prioritários na alocação de incentivos econômicos e fiscais e programas de desenvolvimento sustentável.

A região onde se situam os municípios prioritários é vasta e heterogênea, com extensão Leste-Oeste de aproximadamente $4500 \mathrm{~km}$ e Norte-Sul entre 400 e 500 km. Com exceção de Mucajaí, em Roraima, os demais municípios do Arco Verde localizam-se no chamado Arco do Desmatamento (GOMES et al., 2012). Os municípios prioritários distribuem-se pelos estados do Amazonas, Rondônia, Mato Grosso, Pará, Maranhão e Roraima, ou seja, por seis dos nove estados que compõem a Amazônia Legal. O maior número destes municípios concentra-se no Mato Grosso e no Pará, com 23 e 17 municípios, respectivamente, que historicamente apresentam as maiores taxas de desmatamento. Rondônia contribui com quatro municípios, Amazonas e Maranhão contribuem com dois municípios, e Roraima com um. Os municípios pertencentes ao Arco Verde são listados na Quadro 1 no Anexo e a Figura 2 exibe os limites geográficos da Amazônia Legal e do Arco Verde.

Figura 2: Limites geográficos da Amazônia Legal e do Arco Verde.

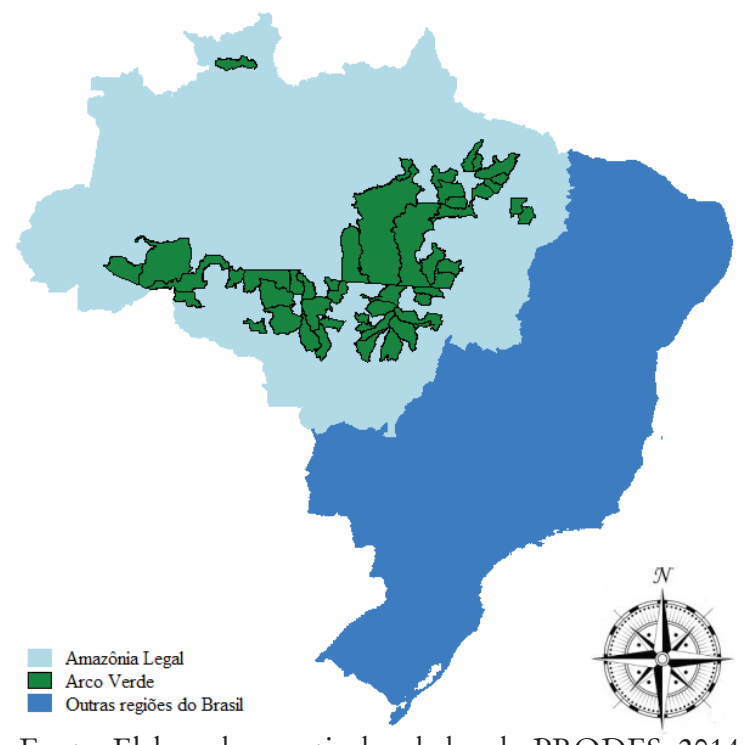

Fonte: Elaborada a partir dos dados do PRODES, 2014.

4 O Arco do Desmatamento é uma região da Amazônia Legal em que a fronteira agrícola avança em direção a floresta e, por isso, apresenta maiores índices de desmatamento. É compreendido por 256 municípios distribuídos em aproximadamente $500 \mathrm{mil} \mathrm{km²}$ de terras que vão do sudeste do Pará para o oeste, passando por Mato Grosso, Rondônia e Acre (IPAM, 2014). 


\subsection{Cenário atual}

A partir da década de 2000 verificou-se a dinamização econômica da Amazônia Legal, propiciada pelo crescimento da agropecuária, da atividade madeireira e pelo polo industrial de Manaus. Em especial, a agropecuária expandiu-se em termos de área ocupada, do volume de produção e da alta de preços, principalmente da carne nos mercados internacionais (GOMES et al., 2012).

Segundo dados da Pesquisa Pecuária Municipal e da Pesquisa Agrícola Municipal (IBGE), os municípios da Amazônia Legal concentraram 32,53\% da área plantada de soja e $37,38 \%$ do rebanho bovino nacional em 2012. No que se refere aos municípios prioritários, estes percentuais foram $8,95 \%$ e 5,7\% respectivamente. Entre 2005 e 2011, o Produto Interno Bruto nos municípios da Amazônia Legal e nos municípios do Arco Verde cresceu em média 14,8\% e 14,9\% respectivamente, enquanto o PIB nacional cresceu $11,62 \%$.

A partir de 2004, ano em que a taxa de desmatamento atingiu o maior valor histórico, entrou em vigor o PPCDAm. O PPCDAm é um instrumento para a operação de planos estratégicos do Governo Federal para a região amazônica e é coordenado pela Casa Civil em parceria com 13 ministérios. Suas metas fazem parte do Plano Nacional de Mudanças Climáticas (PNMC), que prevê a redução de $80 \%$ do desmatamento da Amazônia Legal até 2020, tendo como ponto de partida os 19,5 mil km² desmatados em 2002. É provável que o Plano consiga cumprir a sua meta, visto que entre 2002 e 2014 o desmatamento caiu $73,7 \%$, passando de 19,5 mil km² em 2002 para 5,1 mil km² em 2013 (FUNDO AMAZÔNIA, 2014).

A partir de 2005 houve uma queda acentuada nas taxas de desmatamento que se mantêm até os dias atuais. A literatura atribui a redução do desmatamento às pressões nacionais e internacionais e aos mercados de grãos e de carne. Um estudo do Núcleo de Avaliação de Políticas Climáticas, que fez uso da série histórica de dados de desmatamento produzidos pelo PRODES, mostra que cerca de metade do desmatamento evitado entre 2005 e 2009 pode ser atribuído às políticas ambientais introduzidas na segunda metade dos anos 2000 (ASSUNÇÃO et al., 2012 citado por VALERIANO et al., 2012).

A Figura 3 apresenta o gráfico da evolução do desmatamento $\left(\mathrm{em} \mathrm{km}^{2}\right)$ na Amazônia Legal e nos municípios do Arco Verde entre 2001 e 2012. 
Figura 3: Evolução do desmatamento $\left(\mathrm{em} \mathrm{km}^{2}\right)$ na Amazônia Legal e no Arco Verde entre 2001 e 2012.

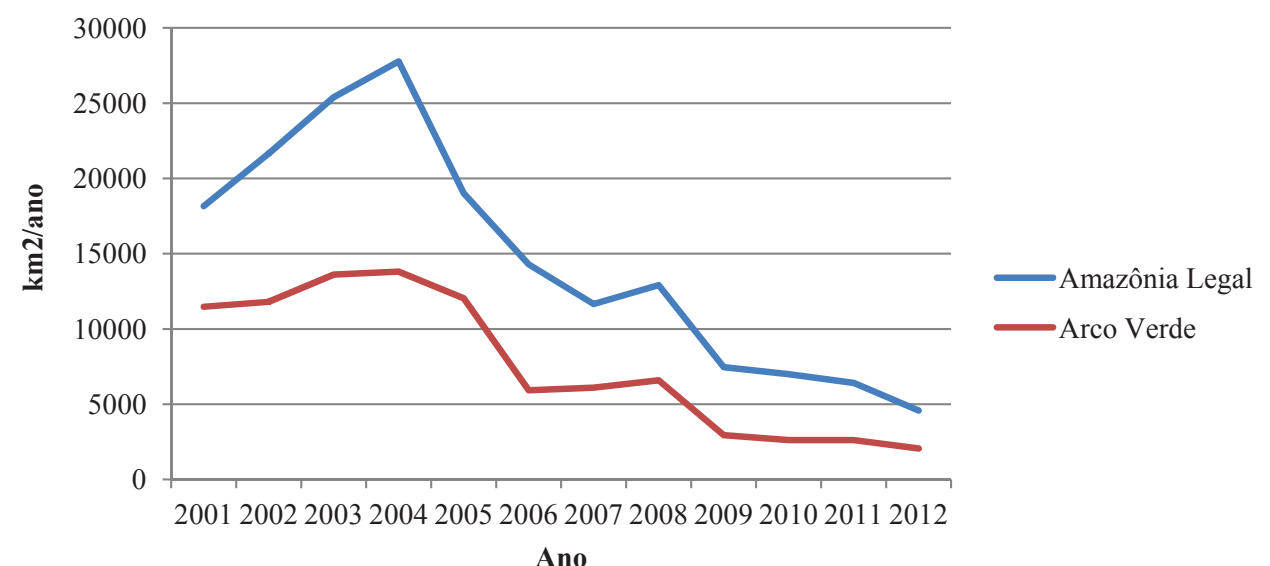

Fonte: PRODES, 2014.

Ainda de acordo com Valeriano et al. (2012), há uma tendência à redução do tamanho das áreas desmatadas. Em 2002, 30\% dos polígonos de desmatamento tinham área menor que 25 hectares, enquanto que em 2011 cerca de 60\% dos polígonos eram menores que 25 hectares.

Além das variáveis que tradicionalmente são consideradas como responsáveis pelo desmatamento, alguns autores consideraram outras variáveis como causas subjacentes do desmatamento, como a não existência de uma estrutura administrativa responsável por questões ambientais. De acordo com os dados do Perfil dos $\mathrm{Mu}$ nicípios Brasileiros, em 2004 apenas 19 dos 49 municípios prioritários dispunham de Secretaria ou Departamento de Meio Ambiente, enquanto em 2012 este número aumentou para 45. Embora este número tenha aumentado consistentemente ao longo do período considerado na amostra, este número ainda não é plenamente satisfatório dado a importância ambiental que estes municípios possuem.

A Figura 4 mostra a distribuição do desmatamento dos municípios da Amazônia Legal entre os estados para os anos 2005 e 2012. Conforme pode ser visto na Figura 4 (a), os estados que mais desmataram em termos absolutos nos anos considerados foram Pará e Mato Grosso, seguidos por Maranhão e Rondônia. Em termos relativos, porém, os estados com o maior incremento de desmatamento em $2005 \mathrm{em}$ relação ao ano anterior considerando-se a área total de florestas foram Tocantins e Maranhão, seguidos por Rondônia e Mato Grosso. Já em 2012, os estados com maior desmatamento em termos relativos foram Maranhão, Roraima e Tocantins. 
Figura 4: Distribuição do desmatamento $\left(\mathrm{em} \mathrm{km}^{2}\right.$ ) em termos absolutos (a) e em termos relativos (b) entre os estados da Amazônia Legal em 2005 e 2012.

(a)

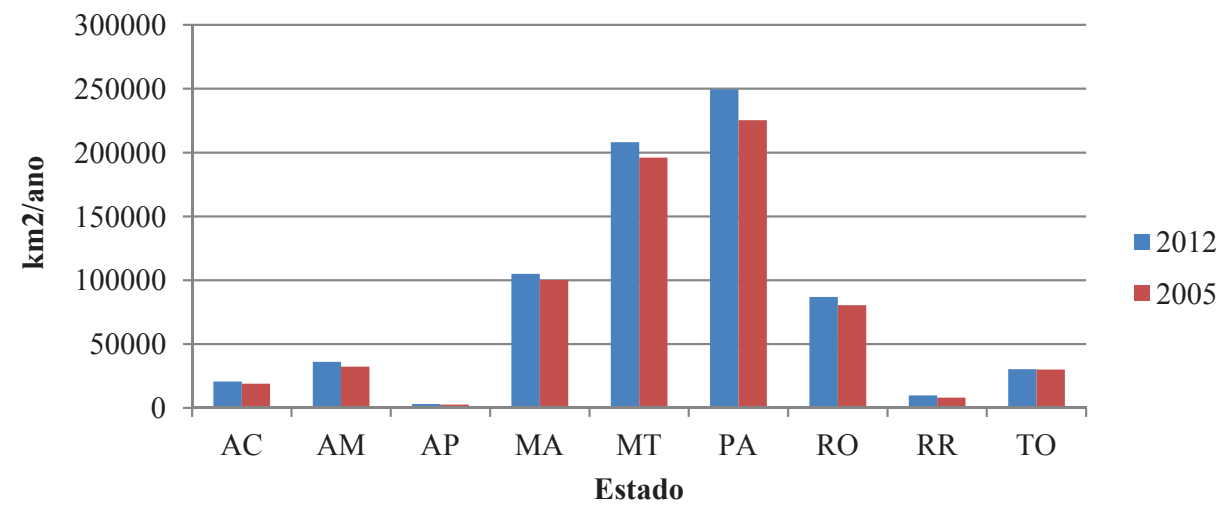

(b)

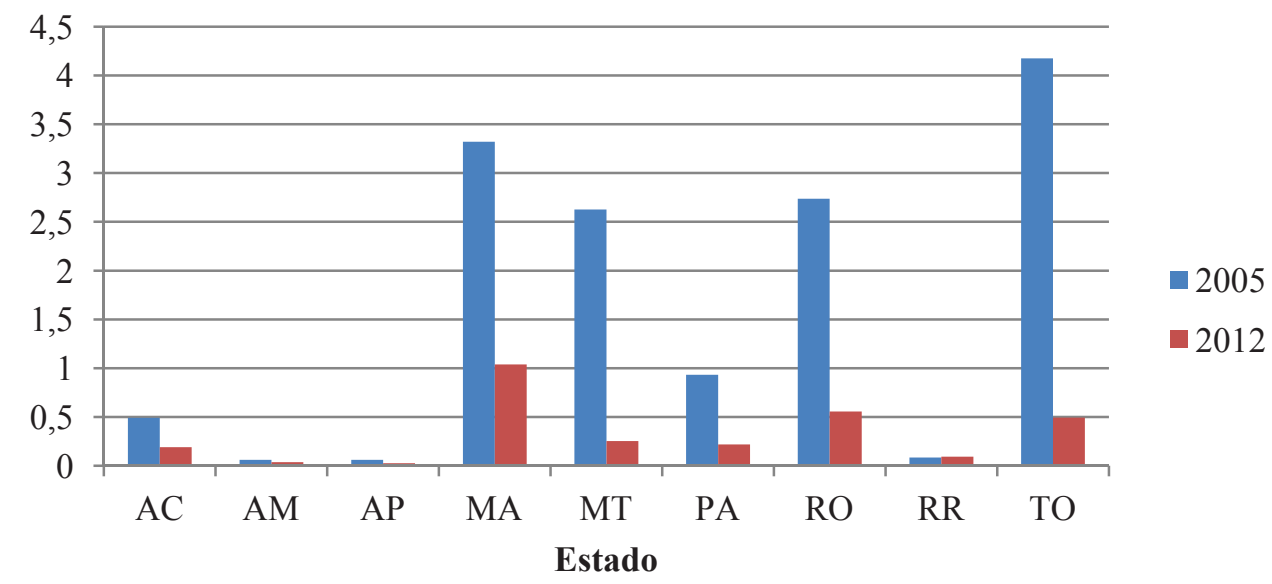

Fonte: PRODES, 2014.

Considerando apenas os estados que abrigam os municípios do Arco Verde, a Figura 5 mostra a participação de cada estado no incremento do desmatamento entre 2011 e 2012, tanto em termos absolutos quanto relativo ao total de área de floresta. De acordo com a Figura 5 (a), Pará e Mato Grosso foram os estados que mais desmataram, em termos absolutos, entre os dois últimos anos do período considerado na análise proposta por este estudo. Considerando-se o desmatamento em termos relativos (b), os estados que alcançaram os maiores índices de desmatamento foram Maranhão e Rondônia. 
Figura 5: Desmatamento por Estado entre 2011 e 2012 para os municípios do Arco Verde em termos absolutos (a) e em termos relativos (b).

(a)

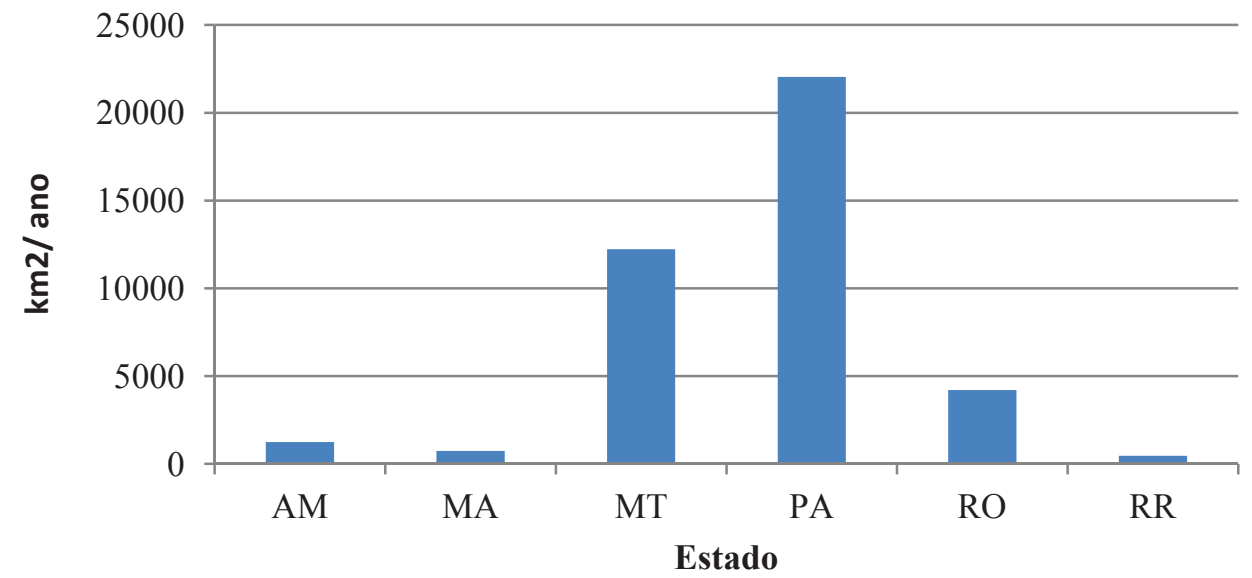

(b)

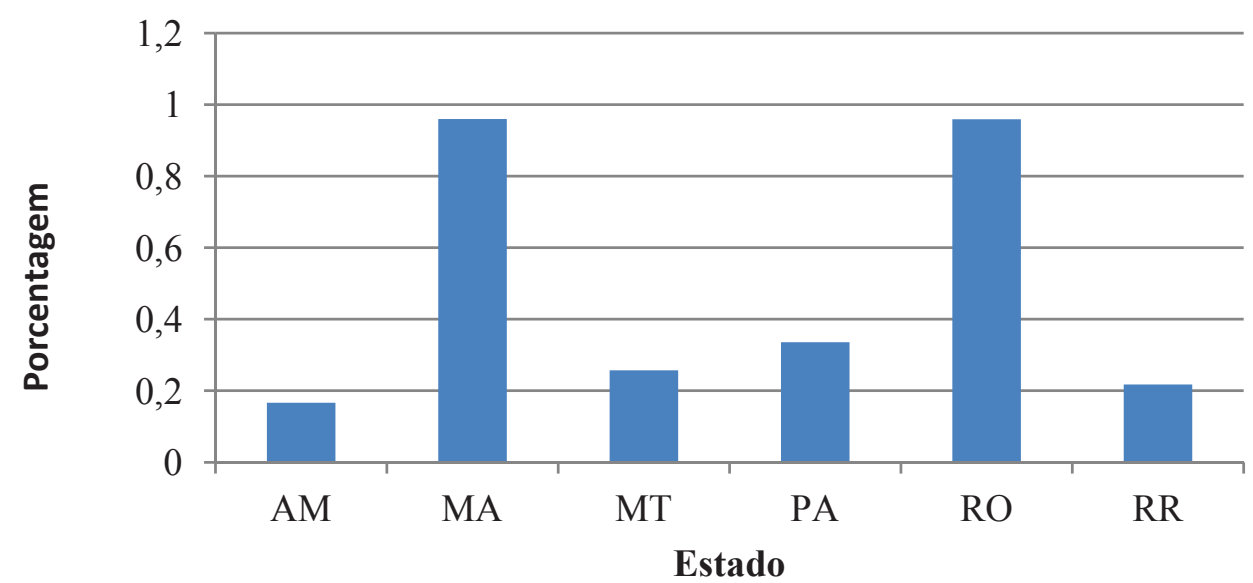

Fonte: PRODES, 2014.

A partir das Figuras 4 e 5, é possível perceber que a configuração do desmatamento entre os estados é similar quando se compara os municípios pertencentes à Amazônia Legal aos municípios pertencentes ao Arco Verde. 


\section{Revisão de literatura}

Conforme exposto anteriormente, muitos autores discutiram em seus trabalhos as principais causas do desmatamento na Amazônia desde a intensificação de sua ocupação.

Reis e Margulis (1991) projetaram as emissões futuras da Amazônia, através da modelagem do processo de desflorestamento. $\mathrm{O}$ modelo desenvolvido pelos autores descreveu a relação entre a densidade espacial das principais atividades econômicas e a fração da área desflorestada, utilizando as variáveis densidade de população, efetivo de gado bovino, área de culturas agrícolas, extração de madeira e rodovias. A variável área agrícola apresentou o maior valor para a elasticidade do desflorestamento, seguida da população e da densidade de rodovias. Foram estimadas equações cross-sections relacionando o crescimento entre 1980 e 1985 à densidade da população, pecuária, áreas agrícolas e extração madeireira em 1980 de modo a viabilizar as previsões dos padrões de crescimento de cada atividade no futuro. Os autores relacionaram dados de desflorestamento com dados de densidade das variáveis selecionadas, que tiveram forte influência na década de 1980, mas que se revelaram mais fracas ou ausentes na década de 90.

Reis (1996) desenvolveu um modelo econométrico com o objetivo de avaliar os efeitos indiretos do Polo Siderúrgico do Carajás sobre o desflorestamento. A análise das interações entre os processos de desflorestamento, ocupação agropecuária, urbanização e industrialização constituiu o ponto principal do modelo. As hipóteses básicas do modelo eram que o crescimento populacional e a expansão da malha rodoviária foram as principais determinantes da ocupação econômica da Amazônia brasileira e que a atividade agropecuária constituiu a principal causa imediata do processo de desflorestamento no período considerado na amostra, tendo a extração madeireira papel secundário.

Andersen e Reis (1997) desenvolveram um modelo de desflorestamento e desenvolvimento econômico para a Amazônia Legal baseando-se nos determinantes da demanda por terra agrícola, isto é, nas interações entre dinâmicas de população, urbanização, crescimento de mercados locais, preços da terra e políticas de governo. $\mathrm{O}$ modelo foi utilizado para avaliar os diferentes instrumentos das políticas de desenvolvimento entre 1970 e 1985. Segundo os autores, a quantidade de terras desflorestadas seria determinada, em sua maior parte, pela demanda por novas terras agrícolas.

Young (1998) estudou os mecanismos que causaram o desflorestamento na Amazônia nas décadas de 1970 e 1980 e os resultados da regressão mostraram uma relação positiva entre a variação da área agrícola, utilizada como proxy do desflorestamento, e as variações no tempo dos preços agrícolas, dos créditos, da construção de rodovias e preços de terras. Para o autor as causas da migração derivaram da concentração de terras, das políticas de exportação, dos programas de desenvolvimento regional, das medidas de austeridade como estratégia para estabilizar a economia sobre o mercado de trabalho e da posterior substituição do crédito subsidiado por uma 
política de indexação mais realista de preços agrícolas na década de 1980. Este modelo buscou explicar a influência das políticas públicas neste período, mas não pôde explicar as dinâmicas do desflorestamento na década de 1990, década em que praticamente já não havia expansão da malha rodoviária, crédito governamental e migrações.

Ferraz (2000) buscou analisar as causas da expansão agrícola e da pecuária entre 1980 e 1995 por meio de modelos de regressão múltipla, relacionando as variáveis dependentes "conversão de florestas em áreas agrícolas" e "conversão de florestas em pecuária” com as variáveis independentes preço da produção, preço de insumos, extensão de rodovias pavimentadas e não pavimentadas e crédito agrícola. $\mathrm{O}$ autor concluiu que a expansão agrícola foi determinada pelos aumentos de preços da terra, redução do salário rural, crédito rural e rodovias. Quanto à expansão da pecuária, os resultados apontaram a expansão da malha rodoviária como a sua causa principal.

Margulis (2003) considerou pequena a participação dos pequenos agricultores no processo de desmatamento, pois de acordo com ele, após tomarem posse da terra e conseguir o título de propriedade, estes agricultores as vendem para os pecuaristas. Entretanto, o autor reconhece o papel dos pequenos e grandes agentes no avanço e consolidação das fronteiras, enfatizando o modelo em que os pequenos agentes estão associados às madeireiras e aos grandes empreendimentos. De acordo como autor, não seriam as estradas em si que levariam ao desflorestamento, mas a viabilidade financeira da pecuária. A redução dos custos de transportes propiciada pelos investimentos nos grandes eixos rodoviários tornou lucrativa a implantação de atividades agropecuárias, antes inviáveis. As melhores condições das rodovias encorajaram os proprietários de terras a aumentarem a produção e a mudarem da agricultura de subsistência para produção comercial.

Rivero et al. (2009) analisaram a evolução das causas imediatas do desmatamento na Amazônia utilizando regressões lineares com dados em painel para o período compreendido entre 2000 e 2006 . O resultado mostrou que a pecuária e a expansão da soja são fortemente correlacionados com o desmatamento e que esta tendência foi reforçada pelo crescimento nacional e internacional da demanda por carne e soja.

Cabral e Gomes (2013) desenvolveram um estudo sobre a gestão ambiental nos municípios do Pará que compõem o Arco do Desmatamento e que se destacam pelos altos índices de desmatamento provocados pela pecuária, produção de soja e silvicultura. Analisaram ainda em que medida as ações públicas em relação a estas atividades respondem ao desmatamento. Para a análise, os autores basearam-se nos dados sobre produção agrícola e pecuária, desmatamento e aparelhamento político-institucional municipais referentes ao período compreendido entre 2000 e 2009. Os autores concluíram que a presença de instituições reguladoras municipais contribuiu para reduzir problemas ambientais.

Martins et al. (2010) construíram um modelo logit multinomial para analisar os determinantes da intensidade do desmatamento na Amazônia Legal. Utilizaram como variáveis dependentes a razão entre a área desmatada acumulada e a área do município, e como variáveis explicativas utilizaram o Produto Interno Bruto, o Im- 
posto Territorial Rural, a densidade populacional, a existência de Secretaria Municipal de Meio Ambiente, as lavouras permanente e temporária, o efetivo bovino e o total de matrículas efetuadas na educação de jovens e adultos. Os autores concluíram que as variáveis lavoura permanente, lavoura temporária, densidade demográfica e efetivo bovino são as principais causas do desmatamento.

\section{Metodologia}

\subsection{Modelo empírico}

O presente artigo pretende desenvolver suas análises utilizando regressões com dados em painel. Esse método permite que sejam combinados os dados de corte transversal com séries temporais, aumentando assim a quantidade de observações disponíveis, o que faz com haja um maior número de graus de liberdade e, consequentemente, menor colinearidade entre as variáveis explicativas (HSIAO, 2006).

O modelo geral para dados em painel é:

$$
Y_{i t}=\beta_{0 i t}+\beta_{1 i t} X_{1 i t}+\ldots+\beta_{k i t} X_{k i t}+\varepsilon_{i t}
$$

em que o subscrito $i$ indica cada indivíduo e o subscrito $t$ indica o período de tempo. $O$ parâmetro $\beta_{\text {oit }}$ corresponde ao parâmetro de intercepto e $\beta_{k i t}$ corresponde ao coeficiente angular da k-ésima variável explicativa do modelo. $\mathrm{O}$ parâmetro $\alpha_{i}$ é o efeito fixo e $\varepsilon_{i t}$ é o erro idiossincrático, que representa os fatores não observados que mudam ao longo do tempo e que afetam $Y_{i t}$ (GUJARATI, 2006).

Os métodos de dados em painel são subdivididos em modelo de dados empilhados (pooled), modelo de efeitos fixos e modelo de efeitos aleatórios. A escolha do modelo que melhor se adequasse aos dados utilizados para a análise proposta por este artigo foi feita de duas formas. Primeiramente foi realizado o teste de Chow para decidir entre o modelopooled e o modelo de efeitos fixos e em seguida foram feitos os testes de Hausman para decidir entre o modelo de efeitos fixos e o modelo de efeitos aleatórios, e o teste do Multiplicador de Lagrange para decidir entre o modelo Pooled e o modelo de efeitos aleatórios. Os testes utilizados são descritos abaixo:

a) Teste de Chow:

$$
F c=\frac{\left[\left(R_{e f}^{2}-R_{\text {pooled }}^{2}\right) / m\right]}{\left[\left(1-R_{e f}^{2}\right) /(N-k)\right]}
$$


L. M. Delazeri - Determinantes do desmatamento nos Municípios ...

em que é o coeficiente de determinação do modelo com efeitos fixos e é o coeficiente de determinação do modelo pooled. Se $F_{c}>F_{\text {tabelado }}$, o modelo de efeitos fixos será o mais adequado.

b) Teste de Hausman:

A estatística do teste de Hausman é obtida a partir da equação:

$$
H=\left(\hat{\beta}_{E A}-\hat{\beta}_{E F}\right)^{\prime}\left(\Sigma_{E F}-\Sigma_{E A}\right)^{-1}\left(\hat{\beta}_{E A}-\hat{\beta}_{E F}\right)
$$

em que $\hat{\beta}_{E A}, \hat{\beta}_{E F}, \Sigma_{E F}$ e $\Sigma_{E A}$ denotam o vetor de coeficientes estimados pelos efeitos aleatórios, o vetor de coeficientes estimados por efeitos fixos, as matrizes de covariância do modelo de efeitos fixos e as matrizes de covariância do modelo de efeitos aleatórios, respectivamente. (PINDYCK e RUBINFELD, 2004)

Hipótese nula: $\left[E\left(\alpha_{i} / X_{k i t}\right)=0\right.$ : não são correlacionados]. Isto é $\alpha_{1}=\alpha_{2}=\alpha_{3} \ldots=\alpha_{k}$ Hipótese alternativa: $\left[E\left(\alpha_{i} / X_{k i t}\right) \neq 0\right.$ : são correlacionados $]$. Ou seja $\alpha_{1} \neq \alpha_{2} \neq \alpha_{3} \ldots \neq \alpha_{k}$

Em outras palavras, a hipótese nula indica que o modelo de efeitos aleatórios é o melhor e a hipótese alternativa indica que o modelo de efeitos fixos é o melhor. A principal diferença entre os modelos é que o modelo de efeitos fixos pressupõe a presença da correlação entre as variáveis explicativas e o efeito fixo, enquanto que o modelo de afeitos aleatórios pressupõe a ausência dessa correlação.

c) Multiplicador de Lagrange:

Avalia se a hipótese de que a variância dos resíduos reflete diferenças individuais é igual à zero. Se a hipótese for rejeitada, o modelo de efeitos aleatórios será preferível ao modelo pooled (GREENE, 2012).

$\mathrm{O}$ método de dados em painel ainda se divide em painel balanceado, que é o painel com todas as informações para todas as observações, painel desbalanceado, que é o painel com informações faltantes, painel curto, que é o painel em que o número de observações para a seção cruzada é maior que o número de séries de tempo, e painel longo, em que ocorre o inverso do painel curto.

\subsubsection{Modelo de efeitos fixos}

De acordo com Gujarati (2006), no modelo de efeitos fixos, embora o intercepto possa diferir entre indivíduos, cada intercepto individual não se altera ao longo do tempo. O principal objetivo da estimação dos efeitos fixos é controlar as características que são específicas dos indivíduos, mas que não variam durante o tempo da série, além de elementos que são capturados através de outras variáveis independentes. 
O modelo geral para efeitos fixos é:

$$
Y_{i t}=\beta_{o i t}+\beta_{1 i t} X_{1 i t}+\ldots+\beta_{k i t} X_{k i t}+\alpha_{i}+\varepsilon_{i t}
$$

A principal diferença entre os modelos (1) e (2) é a inclusão do parâmetro $\alpha_{i}$ em (2), que representa o efeito fixo.

\subsubsection{Fonte de dados e descrição das variáveis}

A variável a ser utilizada como variável independente é o Desmatamento, calculado pelo Instituto Nacional de Pesquisas Espaciais (INPE) com base no Programa de Desflorestamento da Amazônia. Em relação às variáveis explicativas, estas foram escolhidas conforme sugerido pela literatura pertinente. A maior parte delas foi obtida por meio do IBGE e são o efetivo do rebanho bovino municipal, calculado pela Pesquisa Pecuária Municipal; a área plantada de soja, as áreas plantadas de milho, arroz e mandioca e a área plantada de lavoura permanente, calculadas pela Pesquisa Agrícola Municipal; a renda per capita, definida como a razão entre o PIB, expresso em R \$ de 2005 deflacionados pelo Índice de Preços do Consumidor Autônomo (IPCA); o total da população; e a densidade demográfica, definida como a razão entre a população e a área do município.

Foram utilizadas também como variáveis explicativas o número total de matrículas efetuadas na educação de jovens e adultos, obtidas através do Instituto $\mathrm{Na}$ cional de Estudos e Pesquisas Educacionais Anísio Teixeira (INEP) e a variável dummy de existência de Secretaria ou Departamento de Meio Ambiente no município, obtida através do Perfil dos Municípios Brasileiros.

Embora muito relevantes para explicar o desmatamento na Amazônia até a década de 1990, os subsídios e créditos do governo diminuíram significativamente após este período e passaram a ter efeitos insignificantes no desmatamento. De acordo com Margulis (2003), atualmente os créditos e subsídios não podem ser considerados como fatores relevantes para explicar o processo de desmatamento na região amazônica.

Apesar de a extração madeireira ser de grande importância para a análise, esta variável não foi incluída no modelo devido ao grande número de observações faltantes. Isso pode se dever, em partes, à grande ilegalidade existente na extração da madeira. Além disso, alguns autores, como Margulis (2003), consideram a extração da madeira minoritariamente como uma atividade fim, mas como um subproduto da derrubada da floresta para a agricultura.

O objetivo inicial deste artigo era fazer a análise das variáveis supracitadas a partir de 2005, ano em que o incremento do desmatamento anual passou a declinar. Entretanto, devido às limitações quanto aos dados, a análise proposta por este artigo se limitou aos anos compreendidos entre 2008 e 2012. 


\subsection{Modelo analítico}

A análise econométrica será feita através de um painel curto e balanceado para os 49 municípios que compõem o Arco Verde.

O modelo utilizado é apresentado a seguir.

$$
\begin{aligned}
& D E S M_{t i}=B O V_{i t}+S O J_{i t}+L V T_{i t}+L V P_{i t}+R P C_{i t}+D E N S_{i t}+E J A_{i t} \\
& +S M A_{i t}+\varepsilon_{i t}
\end{aligned}
$$

em que DESM é o incremento do desmatamento em $\mathrm{km}^{2}$ no ano $t$ em relação ao ano $t-1 ; B O V$ é incremento de cabeças bovinas no ano $t$ em relação ao ano $t-1$, $S O J$ é o incremento da área plantada de soja, em hectares, no ano $t$ em relação ao ano $t-1, L V T$ é o incremento do somatório da área plantada em hectares de arroz, milho e mandioca no ano $t$ em relação ao ano $t-1, L V P$ é a área plantada em hectares de lavoura permanente no ano $t$ em relação ao ano $t-1, R P C$ é o incremento do PIB per capita no ano $t$ em relação ao ano $t-1, D E N S$ é o incremento da densidade demográfica no ano $t$ em relação ao ano $t-1, E J A$ é o incremento do número de matrículas efetuadas na educação de jovens e adultos no ano $t$ em relação ao ano $t-1$ e $S M A$ é uma dummy de existência de Secretaria ou Departamento de Meio Ambiente no município $i$, que assumiu valor 1 para a existência e 0 para a ausência.

O método escolhido para a estimação do modelo foi o Modelo de Efeitos Fixos que, após os testes de escolha do melhor modelo, foi o que apresentou melhor ajustamento aos dados. O modelo foi aplicado a 245 observações, sendo observações de 49 municípios e 5 anos.

\section{Resultados}

A Tabela 2 exibe as estatísticas descritivas - média e desvio-padrão - para as variáveis utilizadas na análise econométrica. Os resultados encontrados sugerem que o incremento anual médio da área desflorestada para os municípios do Arco Verde foi $68.69 \mathrm{~km}^{2}$, o incremento anual médio do efetivo bovino foi de 16883,42 cabeças, o incremento anual médio da área plantada de soja foi de 3027,12 hectares, o incremento anual médio da área plantada das outras principais culturas temporárias foi 687,88 hectares, o incremento anual médio da área plantada da lavoura permanente foi 52,48 hectares, o incremento anual médio da densidade populacional foi de 0,11 habitantes por $\mathrm{km}^{2}$, o incremento anual médio do PIB per capita foi de 0,75 mil Reais por habitante e o incremento anual médio de matrículas na educação de jovens e adultos foi 8,38 matrículas. 
Tabela 2: Estatísticas Descritivas.

\begin{tabular}{c|c|c}
\hline Variáveis & Média & Desvio-Padrão \\
\hline Desflorestamento* $^{*}$ & 68.69 & 93.73 \\
\hline Efetivo Bovino* & 16683.42 & 46608.09 \\
\hline Área Plantada de Soja* & 3027.12 & 8888.97 \\
\hline $\begin{array}{c}\text { Área Plantada de Arroz, Milho } \\
\text { e Mandioca* }\end{array}$ & 687.88 & 5033.83 \\
\hline $\begin{array}{c}\text { Área Plantada de Lavoura Per- } \\
\text { manente* }\end{array}$ & 52.48 & 965.73 \\
\hline Densidade Populacional* & 0.11 & 0.29 \\
\hline $\begin{array}{c}\text { PIB per capita* } \\
\text { Matrículas na Educação de } \\
\text { Jovens e Adultos* }\end{array}$ & 0.75 & 3.22 \\
\hline \multicolumn{2}{c}{ * incremento anual médio. }
\end{tabular}

Fonte: Elaborada a partir dos resultados obtidos.

Os resultados da estimação econométrica da equação (3) são exibidos na Tabela 3.

Tabela 3: Resultados Econométricos.

\begin{tabular}{c|c}
\hline Variáveis & Coeficientes e Erro-Padrão \\
\hline Efetivo Bovino & $0.0002531 * \%$ \\
$(0.000109)$ \\
\hline Área Plantada de Soja & 0.0002548 \\
& $(0.000669)$ \\
\hline Área Plantada de Arroz, & -0.0005212 \\
Milho e Mandioca & $(0.001016)$ \\
\hline Área Plantada de Lavoura & 0.006710 \\
Permanente & $(0.004659)$ \\
\hline Densidade Populacional & -18.23312 \\
\hline PIB per capita & $(18.86477)$ \\
\hline Matrículas na Educação de & 1.031646 \\
Jovens e Adultos & $(1.435983)$ \\
\hline Secretaria Municipal de Meio & -0.0068136 \\
Ambiente & $(0.01364)$ \\
\hline
\end{tabular}

Nota: **\% e ${ }^{* *}$ indicam níveis de significância de $1 \%$ e $5 \%$, respectivamente. Fonte: Elaborada pela autora a partir dos resultados obtidos. 
Os resultados exibidos pela tabela sugerem que, dentre as variáveis tradicionalmente apontadas na literatura como responsáveis pelo desmatamento na Amazônia Legal, apenas o efetivo bovino foi significativo, indicando que para cada aumento de 1000 cabeças bovinas, a área desmatada sofreu um aumento de $0,2531 \mathrm{~km}^{2}$. A variável Área Plantada de Soja não foi significativa e umas das possíveis razões para este resultado é que, dentre os 49 municípios analisados, apenas 28 apresentaram produção do grão nos anos considerados, sendo eles majoritariamente municípios mato-grossenses. Este resultado é condizente com o afirmado por Gomes et al. (2012), que diz que o desmatamento na Amazônia e, em especial, nos municípios prioritários é determinado por características diferenciadas, dependendo do perfil dos seus agentes e do tipo de atividade econômica que o ocasiona. É possível que se fossem considerados apenas os municípios do Mato Grosso, a área plantada de soja apresentaria uma relação positiva e significativa com a área desmatada.

Conforme os resultados de outros autores já discutidos neste estudo, as áreas plantadas com outras principais culturas temporárias e com culturas permanentes não foram significativas para explicar o incremento do desmatamento. De acordo com Gomes et al. (2012), embora possa apresentar alguma relevância para o desmatamento, a lavoura não tem o mesmo impacto que a pecuária devido ao uso mais intensivo da terra e à produção localizada. Deve-se considerar, contudo, os efeitos indiretos, como a construção e pavimentação de estradas para o escoamento da produção, que criam novos eixos de desmatamento.

O último censo do IBGE mostra que a Amazônia apresentou expressivo crescimento populacional, especialmente o urbano, entre 2000 e 2010 , e que os municípios prioritários seguem esta mesma tendência de crescimento. $\mathrm{O}$ crescimento populacional no Arco Verde no período supracitado foi de $34,5 \%$, sendo $42 \%$ o crescimento urbano. $\mathrm{O}$ resultado encontrado neste estudo em relação à densidade demográfica é similar ao encontrado por diversos autores, que argumentam que o crescimento populacional não contribui para o aumento do desmatamento.

No que se refere ao PIB per capita, os resultados indicam que os benefícios do desmatamento nos municípios prioritários são distribuídos de forma excludente, uma vez que o desmatamento não foi significativamente acompanhado do aumento de PIB per capita. A variável educação de jovens e adultos não foi significativa, indicando que números adicionais de matrícula não contribuem para reduzir o incremento de área desmatada.

Outra variável que se mostrou significativa foi a variável dummy de existência de Secretaria ou Departamento Municipal de Meio Ambiente. De acordo com o resultado, a existência deste órgão municipal contribui para que o incremento anual de desmatamento seja reduzido em $56,68 \mathrm{~km}^{2}$. Este resultado é condizente com o resultado encontrado por Cabral e Gomes (2013), que sugerem que a existência de instituições reguladoras no âmbito municipal contribui para a redução de problemas ambientais. 


\section{Conclusão}

O desflorestamento da Amazônia tem sido amplamente discutido nos últimos anos. As evidências de que a produção agrícola e a pecuária têm contribuído para o avanço do desmatamento para novas áreas têm se tornado cada vez mais fortes. Além das mudanças socioeconômicas, as implicações do avanço da fronteira agrícola em direção às áreas de floresta consistem em perda de biodiversidade, redução no fornecimento de serviços ecológicos e estresse climático.

Este estudo propôs determinar e quantificar as causas do desmatamento recente nos municípios do Arco Verde utilizando a especificação econométrica de Efeitos Fixos. Além das variáveis já tradicionalmente utilizadas para explicar o desmatamento na Amazônia, incluiu-se outras variáveis apontadas pela literatura recente como possíveis players no desmatamento da floresta amazônica.

A análise dos players do desmatamento na região do Arco Verde indicou que, entre as variáveis tradicionalmente apontadas na literatura como responsáveis pelo desmatamento na Amazônia Legal, apenas o efetivo bovino foi relevante, o que sugere que o avanço da pecuária continua sendo um dos principais determinantes do desmatamento nos municípios do Arco Verde. Conforme apontado por Rivero et al. (2009), as motivações para a expansão da pecuária bovina na Amazônia continuarão ocorrendo, pois esta atividade exige baixos níveis de capital, pouco preparo para o solo e poucas restrições relacionadas ao relevo.

Segundo Vale e Andrade (2012), em se tratando da relação entre pecuária e perda de florestas na Amazônia, o consenso de que a intensificação da pecuária é a solução para o problema do desmatamento está sendo construído no Brasil, na medida em que essa estratégia permite o aumento da produção paralelo à redução do desmatamento. Nesse contexto, deve-se, então, reverter a pecuária extensiva, com baixa densidade do rebanho, para a intensificação da atividade, de forma a reduzir o seu avanço sobre novas áreas via desmatamentos. É importante salientar, entretanto, que mesmo que a intensificação da atividade pecuária ocorra em áreas consolidadas devido, principalmente, à menor oferta de áreas florestadas e à existência de melhor infraestrutura de fiscalização, ainda assim existiria o avanço do "desmatamento na fronteira, que tende a acontecer com mais facilidade devido à dificuldade de fiscalização e ao baixo custo de oportunidade dos agentes" (VALE e ANDRADE, 2012).

Em contrapartida, a expectativa de que a produção de soja fosse relevante para o aumento dos índices de desmatamento na região não foi confirmada. $\mathrm{O}$ aumento da produção de soja não acompanhado pelo aumento do desmatamento pode ser justificado pelo aumento da produtividade como estratégia do aumento da produção. Adicionalmente, pode-se dizer que o aumento da produção tenha ocorrido em áreas previamente desmatadas, dispensando a necessidade de desmatar mais áreas de floresta (NEPSTAD et al., 2014). Ainda contrariando as expectativas, o desmatamento nos municípios do Arco Verde não foi acompanhado pelo aumento do PIB per capita, o que indica que os retornos financeiros do desmatamento nos 
municípios prioritários podem ter sido distribuídos de forma excludente.

E importante destacar que, embora a presença de instituições ambientalmente reguladoras no âmbito municipal tenha se mostrado eficaz na redução do desmatamento, deve-se, ainda, considerar a capacidade de atuação das Secretarias e/ ou Departamentos de Meio ambiente municipais.

De modo geral, os resultados obtidos nesse estudo reforçam a necessidade da formulação de políticas públicas que possibilitem processos de produção sustentáveis e que sejam capazes de reverter a tendência de desenvolvimento econômico via desmatamentos. A busca de soluções no que se refere ao desmatamento, tanto nos municípios que formam a região do Arco Verde, como na Amazônia Legal como um todo, implica influir no comportamento social, econômico e político da sociedade e, assim, desenvolver ações para que o desmatamento ilegal seja evitado e para que o desmatamento legal seja minimizado. $\mathrm{O}$ investimento em pesquisas que desenvolvam novas técnicas de manejo dos recursos, a formação de capital humano, ações que induzam à cooperação entre os agentes econômicos, o estabelecimento de ações que garantam o direito de propriedade e a definição das ações entre as esferas políticas são primordiais para o desenvolvimento econômico e social sustentáveis.

As formas mais efetivas para a manutenção do desmatamento em patamares baixos são o incentivo e o investimento em Atividades Produtivas Sustentáveis (APS), como sistemas agroflorestais e manejo sustentável. A existência dessas atividades pode ser considerada como estratégia de prevenção e controle do desmatamento, pois algumas contribuem para a manutenção da floresta, servindo de contenção do desmatamento, ou recuperação de áreas já degradadas. Além disso, os arranjos produtivos locais contribuem para o fortalecimento das APSs, pois promovem o encontro de empresas e empreendimentos em um mesmo território para que a atividade econômica seja desenvolvida em torno de uma especialização produtiva.

Segundo Margulis (2003), uma das possíveis soluções econômicas para os desmatamentos seria taxá-los de forma a fazer os agentes internalizarem os custos ambientais. Uma alternativa equivalente à taxação seria compensar os agentes para que eles não desmatem. De acordo com Gomes et al. (2012), as diferenciações entre os municípios prioritários no que se refere à taxa de desmatamento devem ser levadas em consideração para o desenvolvimento de estratégias de apoio a atividades produtivas sustentáveis. Isso porque nos municípios com elevados índices de desmatamento, propostas que visem à manutenção da floresta poderão ter pouca aplicabilidade e, nesses casos, há a necessidade de iniciativas que constituam alternativas ao uso da floresta.

O licenciamento ambiental e o Cadastro Ambiental Rural também são importantes mecanismos de controle do desflorestamento. Contudo, a existência de gargalos na legislação e na operacionalização representam entraves a serem superados. Sendo assim, a cooperação entre as esferas políticas e a clara designação de responsabilidades entre elas constituem maneiras de eliminar, ou pelo menos reduzir, a existência destes gargalos. Para manter as metas de redução do desmatamento sugere-se desenvolver políticas de implantação e expansão de unidades de 
conservação e reservas florestais, regular os títulos de terra e integrar as políticas macroeconômicas regional e nacional.

\section{Referências}

ANDERSEN, E.; REIS, E. Deforestation and Government Policy in the Brazilian Amazon: an Econometric Analysis. Texto para discussão 513. IPEA. Rio de Janeiro, 1997.

ASSUNÇÃO, J. et al. A Queda do Desmatamento na Amazônia: Preços ou Políticas? Sumário Executivo. Climate Policy Initiative. Núcleo de Avaliações de Políticas Climáticas, PUC-Rio. Rio de Janeiro, 2012.

CABRAL, E. R.; GOMES, S. C. Gestão Pública em Municípios com Forte Correlação entre Desmatamento e Expansão da Pecuária, da Soja e da Madeira. Ensaios FEE. v.34, n.1, p. 167-194. Porto Alegre, 2013.

FEARNSIDE, P. M. Modelos de uso de terra predominantes na Amazônia: Um desafio para sustentabilidade. 103-154. In: A. Rivas \& C.E.C. Freitas (eds.) Amazônia: Uma Perspectiva Interdisciplinar. Centro de Ciências do Meio Ambiente, Editora da Universidade do Amazonas (EDUA), Manaus-Amazonas. 271 p. 2002.

FEARNSIDE, P. M. Desmatamento na Amazônia brasileira: história, índices e consequências. Megadiversidade. vol. 1, n. 1, 2005.

FERRAZ, C. M. Measuring the Causes of Deforestation, Agriculture, Land Conversion and Cattle Ranching Growth: Evidence from de Amazon.IPEA. Rio de Janeiro, 2000.

FUNDO AMAZÔNIA. Detalhamento das Ações de Prevenção e Controle do Desmatamento na Amazônia Legal. Estratégias, metas e políticas do Plano de Ação para a Prevenção e Controle do Desmatamento na Amazônia Legal - PPCDAM. <http://www.fundoamazonia.gov.br/FundoAmazonia/fam/site_pt/Esquerdo/ fundo_amazonia1.html>.Acesso em: 19/05/2014.

GOMES, C. V. et al. Oportunidades de Apoio a Atividades Produtivas Sustentáveis na Amazônia. Subsídio para Debate. Fundo Amazônia. Brasília, 2012.

GRENE, W. H. Econometric Analysis. New York. Person, 2012.

GUJARATI, D. Econometria Básica. Ed Bookman. 4ª Edição, 2006. 
HSIAO, C. Panel Data Analysis - Advantages and Challenges. Working Paper, Institute of Economic Policy Research, 2006.

INSTITUTO BRASILEIRO DE GEOGRAFIA E ESTATÍSTICA (IBGE). Perfil dos Municípios Brasileiros 2012. Rio de Janeiro, 2012.

INSTITUTO BRASILEIRO DE GEOGRAFIA E ESTATÍ́STICA (IBGE). Pesquisa Pecuária Municipal 2012. Rio de Janeiro, 2012.

INSTITUTO BRASILEIRO DE GEOGRAFIA E ESTATÍSTICA (IBGE). Pesquisa Agrícola Municipal. Rio de Janeiro, 2012.

INSTITUTO DE PESQUISA AMBIENTAL DA AMAZÔNIA (IPAM). A importância das florestas em pé. <http://www.ipam.org.br/saiba-mais/A-importancia-das-florestas-em-pe/1>. Acesso em: 20/05/2014.

INSTITUTO DE PESQUISA AMBIENTAL DA AMAZÔNIA (IPAM). Glossário. Disponível em: <http://www.ipam.org.br/abc/glossario>. Acesso em: 21/05.2014.

INSTITUTO NACIONAL DE ESTUDOS E PESQUISAS EDUCACIONAIS ANÍSIO TEIXEIRA (INEP). Matrícula de Jovens e Adultos. 2012.

INSTITUTO NACIONAL DE PESQUISAS ESPACIAIS (INPE). Programa de Desflorestamento da Amazônia (PRODES). <http://www.dpi.inpe.br/prodesdigital/prodesmunicipal.php>. Acesso em: 19/05/2014.

MACHADO, L. O. R. Desflorestamento na Amazônia Brasileira: Ação Coletiva, Governança e Governabilidade em Área de Fronteira. Sociedade e Estudo, Brasília, v.24, n.1, p. 115-147, jan/abr. 2009. Crossef http://dx.doi.org/10.1590/s010269922009000100006

MARGULIS, S. Causas do Desmatamento da Amazônia Brasileira. Banco Mundial. Brasília, 2003.

MARTINS, C. E. R. et al. Causas dos Determinantes da Intensidade do Desmatamento na Amazônia Legal: Uma Abordagem Multinomial.. In: XV Encontro Regional de Economia, Fórum BNB de Desenvolvimento, 2010, Fortaleza. Anais do XV Encontro Regional de Economia, Fórum BNB de Desenvolvimento, 2010. v. 1.

MELZ, L. J. et al. Determinantes da demanda internacional de carne bovina brasileira: evidências de quebras estruturais. Revista de Economia e Sociologia Rural. vol.52, n.4, p. 743-760. 2014. Crossef http://dx.doi.org/10.1590/S0103-20032014000400007 
NEPSTAD, D. et al. Slowing Amazon deforestation through public policy and interventions in beef and soy supply chains. Science. vol. 344, n. 6188, p. 1118-1123. 2014. Crossef http://dx.doi.org/10.1126/science. 1248525

OLIVEIRA, A. U. BR-163 Cuiabá-Santarém: Geopolítica, Grilagem, Violência e Mundialização. In Maurício Torres (Org). Amazônia Revelada: Os Descaminhos ao Longo da BR-163. Brasília: CNPQ, 2005.

PINDYCK, R. S.; RUBINFELD, D. L.; Econometria: modelos e previsões. Rio de Janeiro. Elsevier, 2004.

REIS, E. Os Impactos do Polo Siderúrgico de Carajás no Desflorestamento da Amazônia Brasileira. A Economia Brasileira em Perspectiva. IPEA. v.2, p. 691-715. Rio de Janeiro, 1996.

REIS, E.; MARGULIS, S. Perspectivas Econômicas do Desflorestamento na Amazônia. Texto para discussão 215. IPEA. Rio de Janeiro, 1991.

RIVERO, et al. Pecuária e Desmatamento: Uma Análise das Principais Causas Diretas do Desmatamento da Amazônia. Nova Economia. v.19, p. 41-66. Belo Horizonte, 2009.

RODRIGUES, R. L. V. Análise dos Fatores Determinantes do Desflorestamento na Amazônia Legal. COPPE/UFRJ. Rio de Janeiro, 2004.

SUPERINTENDÊNCIA DO DESENVOLVIMENTO DA AMAZÔNIA (SUDAM). Legislação. <http://www.sudam.gov.br/amazonia-legal>. Acesso em: 19/05/2014.

VALE, P. M.; ANDRADE, D. C. Comer carne e salvar a Amazônia? A produtividade da pecuária em Rondônia e sua relação com o desmatamento. Estudos Sociedade e Agricultura. vol. 20, n. 2, p. 381-408. Rio de Janeiro, 2012.

VALERIANO, D. M. et al. Dimensões do Desmatamento na Amazônia Brasileira. In George Martine. População e Sustentabilidade na era das Mudanças Ambientais Globais: Contribuições para uma Agenda Brasileira. p.223-238, Inprint, 2012.

YOUNG, C. Public Policies and Deforestation in the Brazilian Amazon. Planejamento e Políticas Públicas. IPEA, n.18. Rio de Janeiro, 1998. 


\section{Anexo}

Quadro 1: Municípios pertencentes ao Arco Verde por Estado.

\begin{tabular}{|c|}
\hline Municípios pertencentes ao Arco Verde \\
\hline Mato Grosso \\
\hline $\begin{array}{c}\text { Alta Floresta, Alto Boa Vista, Aripuanã, Brasnorte, Cláudia, Colniza, Confresa, Cotri- } \\
\text { guaçu, Feliz Natal, Gaúcha do Norte, Grajaú, Juara, Juína, Marcelândia, Nova Bandei- } \\
\text { rantes, Nova Maringá, Nova Ubiratã, Paranaíta, Peixoto de Azevedo, Porto dos Gaú- } \\
\text { chos, Querência, Santa Carmen, São Félix do Araguaia, Vila Rica. }\end{array}$ \\
\hline Pará \\
\hline $\begin{array}{c}\text { Altamira, Brasil Novo, Cumaru do Norte, Dom Eliseu, Itupiranga, Marabá, Moju, } \\
\text { Novo Progresso, Novo Repartimento, Pacajá, Paragominas, Rondon do Pará, Santa } \\
\text { Maria das Barreiras, Santana do Araguaia, São Félix do Xingu, Tailândia, Ulianópolis. }\end{array}$ \\
\hline Rondônia \\
\hline Machadinho D’oeste, Nova Mamoré, Pimenta Bueno, Porto Velho. \\
\hline Maranhão \\
\hline Amarante do Maranhão. \\
\hline Amazonas \\
\hline Boca do Acre, Lábrea. \\
Roraima \\
\hline Mucajaí. \\
\hline
\end{tabular}

Fonte: PRODES, 2014.

Recebido em 29.11.14

Aprovado em 08.12.15 